Sabine Rudnik-

Schöneborn, MD

Jan Senderek, MD

Joanna C. Jen, MD

Gunnar Houge, MD

Pavel Seeman, MD

Alena Puchmajerová, MD

Luitgard Graul-

Neumann, MD

Ulrich Seidel, MD

Rudolf Korinthenberg, MD

Janbernd Kirschner, MD

Jürgen Seeger, MD

Monique M. Ryan, MD

Francesco Muntoni, MD

Maja Steinlin, MD

Laszlo Sztriha, MD

Jaume Colomer, MD

Christoph Hübner, MD

Knut Brockmann, MD

Lionel Van Maldergem, MD

Manuel Schiff, MD

Andreas Holzinger, MD

Peter Barth, MD

William Reardon, MD

Michael Yourshaw

Stanley F. Nelson, MD

Thomas Eggermann, PhD

Klaus Zerres, MD

Correspondence to

Dr. Rudnik-Schöneborn:

srudnik-schoeneborn@ukaachen.de

Editorial, page 426

Supplemental data at www.neurology.org

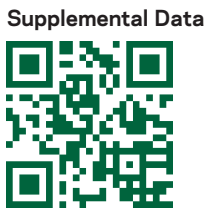

\section{Pontocerebellar hypoplasia type 1}

\author{
Clinical spectrum and relevance of EXOSC3 mutations
}

\section{ABSTRACT}

Objectives: Pontocerebellar hypoplasia with spinal muscular atrophy, also known as PCH1, is a group of autosomal recessive disorders characterized by generalized muscle weakness and global developmental delay commonly resulting in early death. Gene defects had been discovered only in single patients until the recent identification of EXOSC3 mutations in several families with relatively mild course of PCH1. We aim to genetically stratify subjects in a large and well-defined cohort to define the clinical spectrum and genotype-phenotype correlation.

Methods: We documented clinical, neuroimaging, and morphologic data of 37 subjects from 27 families with $\mathrm{PCH} 1$. EXOSC3 gene sequencing was performed in 27 unrelated index patients of mixed ethnicity.

Results: Biallelic mutations in EXOSC3 were detected in 10 of 27 families (37\%). The most common mutation among all ethnic groups was c.395A>C, p.D132A, responsible for 11 (55\%) of the 20 mutated alleles and ancestral in origin. The mutation-positive subjects typically presented with normal pregnancy, normal birth measurements, and relative preservation of brainstem and cortical structures. Psychomotor retardation was profound in all patients but lifespan was variable, with 3 subjects surviving beyond the late teens. Abnormal oculomotor function was commonly observed in patients surviving beyond the first year. Major clinical features previously reported in $\mathrm{PCH} 1$, including intrauterine abnormalities, postnatal hypoventilation and feeding difficulties, joint contractures, and neonatal death, were rarely observed in mutation-positive infants but were typical among the mutation-negative subjects.

Conclusion: EXOSC3 mutations account for 30\%-40\% of patients with PCH1 with variability in survival and clinical severity that is correlated with the genotype. Neurology ${ }^{\circledR}$ 2013;80:438-446

\section{GLOSSARY}

EXOSC3 = exosome component 3; $\mathbf{P C H}=$ pontocerebellar hypoplasia; $\mathbf{P C H} 1=$ pontocerebellar hypoplasia with spinal muscular atrophy; RRP40 = ribosomal RNA-processing protein 40; SMA = spinal muscular atrophy.

Pontocerebellar hypoplasia (PCH) denotes a clinically and genetically heterogeneous group of autosomal recessive developmental defects. The rare combination of $\mathrm{PCH}$ and anterior horn cell disease has also been referred to as amyotrophic cerebellar hypoplasia or cerebellar hypoplasia with WerdnigHoffmann disease. ${ }^{1}$ The disorder was designated as $\mathrm{PCH}^{2}$ to distinguish from $\mathrm{PCH} 2$ without anterior horn cell disease; however, this designation did not fully capture the clinical and genetic

From the Institute of Human Genetics (S.R.-S., J. Senderek, T.E., K.Z.), Medical Faculty, University Hospital Aachen, Germany; Departments of Neurology (J.C.J.), Human Genetics (M.Y., S.F.N.), Pathology \& Laboratory Medicine (S.F.N.), and Psychiatry (S.F.N.), University of California, Los Angeles; Center for Medical Genetics and Molecular Medicine (G.H.), Haukeland University Hospital, Bergen, Norway; Department of Child Neurology (P.S.), 2nd Faculty of Medicine, Charles University Prague and University Hospital, Prague; Institute of Biology and Medical Genetics (A.P.), University Hospital Motol, Prague, Czech Republic; Institute of Medical and Human Genetics (L.G.-N.), Department of Pediatrics (U.S.), and Department of Neuropediatrics (C.H.), Charité Universitätsmedizin Berlin, Berlin; Department of Pediatrics (R.K., J.K.), University Medical Center Freiburg, Freiburg; German Clinic for Diagnostics (J. Seeger), Wiesbaden, Germany; Royal Children's Hospital (M.M.R.), Murdoch Childrens Research Institute, University of Melbourne, Australia; UCL Institute of Child Health \& Great Ormond Street Hospital for Children (F.M.), London, UK; Department of Neuropediatrics (M. Steinlin), University Children's Hospital Bern, Bern, Switzerland; Department of Pediatrics (L.S.), University of Szeged, Hungary; Unitat de Patologia Neuromuscular (J.C.), Servei de Neurologica, Hospital Sant Joan de Déu, Barcelona, Spain; Department of Pediatrics and Pediatric Neurology (K.B.), Faculty of Medicine, University of Göttingen, Göttingen, Germany; Centre for Human Genetics (L.V.M.), Université de Franche-Comté, Besanson; Department of Child Neurology and Metabolic Diseases (M. Schiff), Hospital Robert Debré, Paris, France; Department of Pediatrics, Dr. von Haunersches Kinderspital (A.H.), Friedrich-Baur-Institut (J. Senderek), Ludwig-Maximilian-Universiät München, Munich, Germany; Division of Pediatric Neurology (P.B.), Emma Children's Hospital/Academic Medical Center, University Hospital Amsterdam, the Netherlands; and Our Lady's Hospital for Sick Children (W.R.), Crumlin, Dublin, Ireland.

Go to Neurology.org for full disclosures. Funding information and disclosures deemed relevant by the authors, if any, are provided at the end of the article. 
heterogeneity within each group. ${ }^{3}$ The most important differential diagnosis of $\mathrm{PCH} 1$ is infantile spinal muscular atrophy (SMA, OMIM 253300), which is a caused by mutations in the SMN1 gene. In patients with PCH1, no mutations in SMN1 have yet been found, thus PCH1 appears a distinct entity despite shared involvement of spinal motor neurons.

In PCH1, mutations were described in single patients only ${ }^{4,5}$ up to the recent discovery of the EXOSC3 gene. ${ }^{6}$ EXOSC 3 encodes exosome component 3 (EXOSC3), also known as the ribosomal RNA-processing protein 40 (RRP40). EXOSC3 is a core component of the human RNA exosome complex that is evolutionarily conserved and important in RNA metabolism.

Although most patients with $\mathrm{PCH} 1$ reported to date conformed to the classical description of severe phenotype with onset prenatally or shortly after birth and death within the first year, some patients showed longer survival and a milder course. ${ }^{7,8}$ We aim to investigate a large panel of unselected subjects for further genotype-phenotype correlation to ascertain the contribution of mutations in EXOSC 3 and to better define the clinical spectrum of PCH1.

METHODS We collected clinical and pathoanatomical details of 27 families with $\mathrm{PCH} 1$ recruited over many years from different countries worldwide. All families were compatible with autosomal recessive inheritance. EXOSC3 gene analysis was performed by Sanger sequencing of all 4 exons and flanking introns as previously described. ${ }^{\circ}$

Standard protocol approvals, registrations, and patient consents. The study protocol was approved by the Institutional Review Board of the University Hospital RWTH Aachen. The inclusion criteria of at least one patient per family for genetic analysis were 1) presence of hypotonia, 2) evidence of neurogenic changes in the muscle by electromyogram, muscle biopsy, or anterior horn cell loss in the spinal cord by autopsy suggestive of spinal muscular atrophy, 3) symmetrical volume loss of the cerebellum by MRI or autopsy, and 4) exclusion of a biallelic deletion/mutation of the SMN1 gene. A signed patient consent-to-disclose form was obtained for photographs of recognizable patients.

RESULTS Mutation analysis. Homozygous or compound heterozygous mutations of EXOSC3 were detected in 15 patients of 10 families (table 1; figure 1). This corresponds to a diagnostic yield of $37 \%$ in the unselected cohort of 27 families. The most common mutation among all ethnic groups was c.395A $>$ C, p. D132A, which was seen in 11 (55\%) of the 20 mutated alleles. ${ }^{6}$ A region of shared haplotypes of up to $1 \mathrm{cM}$ observed in families harboring c.395A $>\mathrm{C}$ suggests an ancestral origin for this mutation (table e-1 on the
Neurology ${ }^{\circledR}$ Web site at www.neurology.org). Family 9 had a compound heterozygous mutation including c.712T $>$ C, p.W238R. The c.92G $>$ C, p.G31A mutation was detected in the 2 Eastern European families (families 7 and 9); shared haplotype spanning EXOSC3 in these 2 families is consistent with a founder mutation (table e-1). W238 and G31 are strictly evolutionarily conserved more than D132; all are located in functionally important motifs that alterations in these 3 residues are predicted to exert detrimental effects by in silico analysis as well as in their inability to rescue the mutant exosc3-knockdown phenotype in zebrafish embryos. ${ }^{6}$

We discovered 3 novel single nucleotide indel mutations: c.226dupG in family 4, c.155delC in family 8, and c.551delG in family 10. Furthermore, we observed a missense mutation c. $2 \mathrm{~T}>\mathrm{C}$, which alters the methionine-encoding start codon AUG, with the next in-frame AUG located more than 500 bases downstream, thereby expressing only the last 100 amino acids in this 275 residue protein. These mutations are predicted to result in null alleles.

Clinical features. The common clinical features of patients with EXOSC3 mutations (table 1) include severe hypotonia, mostly absent motor or speech development, oculomotor dysfunction, and lack of fixation. Birth measurements were generally normal, and progressive microcephaly was documented in 6 of 10 patients where measurements were available (table 1). Head circumference regressed to mild to moderate microcephaly up to $-3.5 \mathrm{SD}$ but remained normal in some long-surviving patients (2-1, 3-1). Muscle tone was generally reduced but spasticity, increased tendon reflexes, and dystonic movements were recorded in 2 sibs of family 1 , before flaccid pareses and reduced muscle tone was seen some years later. Epileptic seizures occurred in 3 patients and included absence epilepsy in patient 2-1 (responsive to valproic acid) and infantile spasms in 2 sisters $(5-1,5-2)$. Available autopsy specimens consistently demonstrated a loss of neurons in the cerebellum, parts of the midbrain, and the anterior spinal cord.

Despite the general consistency in all mutationpositive subjects in the clinical manifestations of hypotonia, progressive muscular atrophy, and global developmental delay, there was variation in the clinical presentation and lifespan that was correlated with the genotype:

Families 1-3 (mild PCH1) (figure 2): Patients appeared normal at birth but presented with psychomotor retardation within 6 months of life, had preserved respiratory function, showed little neurologic decline or regression, and survived beyond early infancy even into adulthood. Patients with mild PCH1 all shared the genetic feature of harboring homozygous c.395A >C, p.D132A mutations. 


\begin{tabular}{|c|c|c|c|c|c|c|c|c|c|c|c|c|c|c|c|}
\hline Table 1 & Clinical feat & ures of 15 pat & ients ou & it of $10 \mathrm{f}$ & amilies with & mutations, arr & ranged by $d$ & ecreasing ag & e (at death) of & the index pa & tient & & & & \\
\hline $\begin{array}{l}\text { Patient } \\
\text { (M/F)/origin }\end{array}$ & Mutations & Consanguinity & $\begin{array}{l}\text { Age } \\
\text { (death) }\end{array}$ & $\begin{array}{l}\text { Age at } \\
\text { onset }\end{array}$ & Pregnancy & $\begin{array}{l}\text { Microcephaly } \\
\text { (age: SDa) }\end{array}$ & $\begin{array}{l}\text { Feeding } \\
\text { difficulties } \\
\text { (age } \\
\text { tube-fed) }\end{array}$ & $\begin{array}{l}\text { Respiratory } \\
\text { failure (age) }\end{array}$ & $\begin{array}{l}\text { Motor } \\
\text { development } \\
\text { (age) }\end{array}$ & $\begin{array}{l}\text { Speech } \\
\text { development }\end{array}$ & $\begin{array}{l}\text { Ophthalmologic } \\
\text { findings }\end{array}$ & $\begin{array}{l}\text { Neurologic } \\
\text { findings }\end{array}$ & $\begin{array}{l}\text { EMG/ } \\
\text { muscle } \\
\text { biopsy } \\
\text { neurogenic }\end{array}$ & $\begin{array}{l}\text { ENG } \\
\text { normal }\end{array}$ & $\begin{array}{l}\text { Brain } \\
\text { imaging }\end{array}$ \\
\hline $\begin{array}{l}\text { 1-1 (F)/ } \\
\text { Turkey }^{\mathrm{b}}\end{array}$ & $\begin{array}{l}\text { c.395A }>C \text {, } \\
\text { p.D132A } \\
\text { (homozygous) }\end{array}$ & + & $20 y$ & $3 \mathrm{mo}$ & Normal & $\begin{array}{l}+(5 \text { y } 3 \mathrm{mo}: \\
-2.5 ; 15 \mathrm{y}: \\
-3.5)\end{array}$ & + & - & $\begin{array}{l}\text { Head control, } \\
\text { sat, crawled } \\
(5-8 \text { y), few } \\
\text { steps with } \\
\text { support } \\
(6-8 \text { y) }\end{array}$ & Single words & Strabismus & $\begin{array}{l}\text { Spasticity, } \\
\text { dystonia, } \\
\text { increased } \\
\text { reflexes, } \\
\text { weakness and } \\
\text { hypotonia from } \\
8 \text { y }\end{array}$ & $+l+$ & + & $\mathrm{PCH}$ \\
\hline $\begin{array}{l}1-2(M) / \\
\text { Turkey }^{6}\end{array}$ & $\begin{array}{l}\text { c.395A }>C \text {, } \\
\text { p.D132A } \\
\text { (homozygous) }\end{array}$ & + & $16 y$ & $3 \mathrm{mo}$ & Normal & $\begin{array}{l}+(7 \mathrm{mo:}-1 ; \\
2 \mathrm{y}:-2)\end{array}$ & - & - & Head control & None & Strabismus & $\begin{array}{l}\text { Spasticity, } \\
\text { myoclonus, } \\
\text { trunk } \\
\text { hypotonia, } \\
\text { increased } \\
\text { reflexes }\end{array}$ & $+l+$ & + & $\mathrm{PCH}$ \\
\hline $\begin{array}{l}\text { 2-1 (F)/ } \\
\text { Germany }\end{array}$ & $\begin{array}{l}\text { c.395A }>\text { C, } \\
\text { p.D132A } \\
\text { (homozygous) }\end{array}$ & - & $18 y$ & $<6 \mathrm{mo}$ & Normal & $\begin{array}{l}-(4 \mathrm{y}: 0 \\
18 \mathrm{y}: 0)\end{array}$ & $+(7 y)$ & $+(13 y)$ & $\begin{array}{l}\text { ?, Abduction } \\
\text { pant until } 6 \\
\text { mo (hip } \\
\text { dysplasia) }\end{array}$ & None & $\begin{array}{l}\text { Strabismus, } \\
\text { nystagmus }\end{array}$ & $\begin{array}{l}\text { Hypotonia, } \\
\text { myoclonus, and } \\
\text { absence } \\
\text { epilepsy from } 8 \\
\text { mo }\end{array}$ & $+1+$ & + & $\mathrm{CH}$ \\
\hline $\begin{array}{l}\text { 3-1 (F)/ } \\
\text { Germany }\end{array}$ & $\begin{array}{l}\text { c.395A }>C \text {, } \\
\text { p.D132A } \\
\text { (homozygous) }\end{array}$ & - & $\begin{array}{l}(5 \mathrm{y} \\
4 \mathrm{mo})\end{array}$ & 3-6 mo & Normal & $\begin{array}{l}-(1 \text { y } 6 \mathrm{mo:} 0 \\
4 \text { y: }-0.5)\end{array}$ & $\stackrel{+}{(3 \text { y } 8 \text { mo) }}$ & - & $\begin{array}{l}\text { Head control, } \\
\text { turned around } \\
(7-10 \mathrm{mo})\end{array}$ & None & $\begin{array}{l}\text { Strabismus, } \\
\text { nystagmus }\end{array}$ & Hypotonia & $+l+$ & + & $\mathrm{PCH}$ \\
\hline $\begin{array}{l}4-1(F) / \\
\text { Norway }\end{array}$ & $\begin{array}{l}\text { c.395A }>C, \\
\text { p.D132A; } \\
\text { c.226dupG; } \\
\text { p.D76fs }\end{array}$ & + Remote & $\begin{array}{l}(2 \mathrm{y} \\
3 \mathrm{mo})\end{array}$ & Birth & Normal & $\begin{array}{l}+(1 \text { y } 10 \mathrm{mo:} \\
-3.5)\end{array}$ & - & - & None & None & Normal & Hypotonia & $+/ N A$ & NA & $\begin{array}{l}\text { Cerebellar } \\
\text { atrophy }\end{array}$ \\
\hline $\begin{array}{l}\text { 4-2 (M)/ } \\
\text { Norway }\end{array}$ & $\begin{array}{l}\text { c.395A }>C \text {, } \\
\text { p.D132A; } \\
\text { c.226dupG; } \\
\text { p.D76fs }\end{array}$ & + Remote & (4 mo) & Birth & Normal & NA & - & $+(4 \mathrm{mo})$ & None & None & Normal & Hypotonia & $+l+$ & NA & $\begin{array}{l}\mathrm{PCH}, \text { mega } \\
\text { cisterna } \\
\text { magna }\end{array}$ \\
\hline $\begin{array}{l}\text { 5-1 (F)/ } \\
\text { Germany }\end{array}$ & $\begin{array}{l}\text { c.395A }>C, \\
\text { p.D132A, } \\
\text { c. } 2 T>C\end{array}$ & - & $\begin{array}{l}(2 \mathrm{y} \\
2 \mathrm{mo})\end{array}$ & Birth & Normal & $-(2 y:+1)$ & $+(2 w k)$ & $+(2$ y $2 \mathrm{mo})$ & None & None & Nystagmus & $\begin{array}{l}\text { Hypotonia, } \\
\text { infantile } \\
\text { spasms }<1 \text { y }\end{array}$ & $+1+$ & NA & $\begin{array}{l}\mathrm{CH}, \\
\text { retrocerebellar } \\
\text { cyst }\end{array}$ \\
\hline $\begin{array}{l}\text { 5-2 (F)/ } \\
\text { Germany }\end{array}$ & $\begin{array}{l}\text { c. } 395 \mathrm{~A}>\mathrm{C}, \\
\text { p.D132A, } \\
\text { c. } 2 \mathrm{~T}>\mathrm{C}\end{array}$ & - & $\begin{array}{l}(1 \mathrm{y} \\
2 \mathrm{mo})\end{array}$ & Birth & Normal & - (3 mo: 0) & NA & NA & None & None & Nystagmus & $\begin{array}{l}\text { Hypotonia, } \\
\text { infantile } \\
\text { spasms from } 4 \\
\text { mo }\end{array}$ & $+1+$ & + & $\begin{array}{l}\mathrm{CH}, \\
\text { retrocerebellar } \\
\text { cyst }\end{array}$ \\
\hline $\begin{array}{l}6-1(F) / \\
\text { Australia }^{c_{18}}\end{array}$ & $\begin{array}{l}\text { c. } 395 \mathrm{~A}>\mathrm{C}, \\
\text { p.D132A; } \\
\text { c. } 475- \\
12 \mathrm{~A}>\mathrm{G}\end{array}$ & - & $\begin{array}{l}(2 \mathrm{y} \\
1 \mathrm{mo})\end{array}$ & Birth & Normal & $+(2 y:-2)$ & $+(8 \mathrm{mo})$ & $+(2 y)$ & None & None & Normal & Hypotonia & + /NA & + & $\begin{array}{l}\mathrm{CH}, \\
\text { retrocerebellar } \\
\text { cyst }\end{array}$ \\
\hline $\begin{array}{l}7-1(M) / \\
\text { Serbia }\end{array}$ & $\begin{array}{l}\text { c.92G }>\text { C, } \\
\text { p.G31A } \\
\text { (homozygous) }\end{array}$ & - & $\begin{array}{l}(1 \mathrm{y} \\
3 \mathrm{mo})\end{array}$ & Birth & Normal & + (4 mo: -2.5$)$ & $+(2 w k)$ & $+(5 \mathrm{mo})$ & None & None & Normal & Hypotonia & $+1+$ & NA & $\begin{array}{l}\mathrm{PCH}, \text { mega } \\
\text { cisterna magna }\end{array}$ \\
\hline $\begin{array}{l}8-1(F) / \\
U^{25}\end{array}$ & $\begin{array}{l}\text { c.395A>C, } \\
\text { p.D132A; } \\
\text { c.155delC, } \\
\text { p.52fs }\end{array}$ & - & $(9 \mathrm{mo})$ & Birth & Normal & + & $+(1 \mathrm{mo})$ & $+(9 \mathrm{mo})$ & None & None & Normal & Hypotonia & $+1+$ & NA & $\mathrm{CH}$ \\
\hline
\end{tabular}



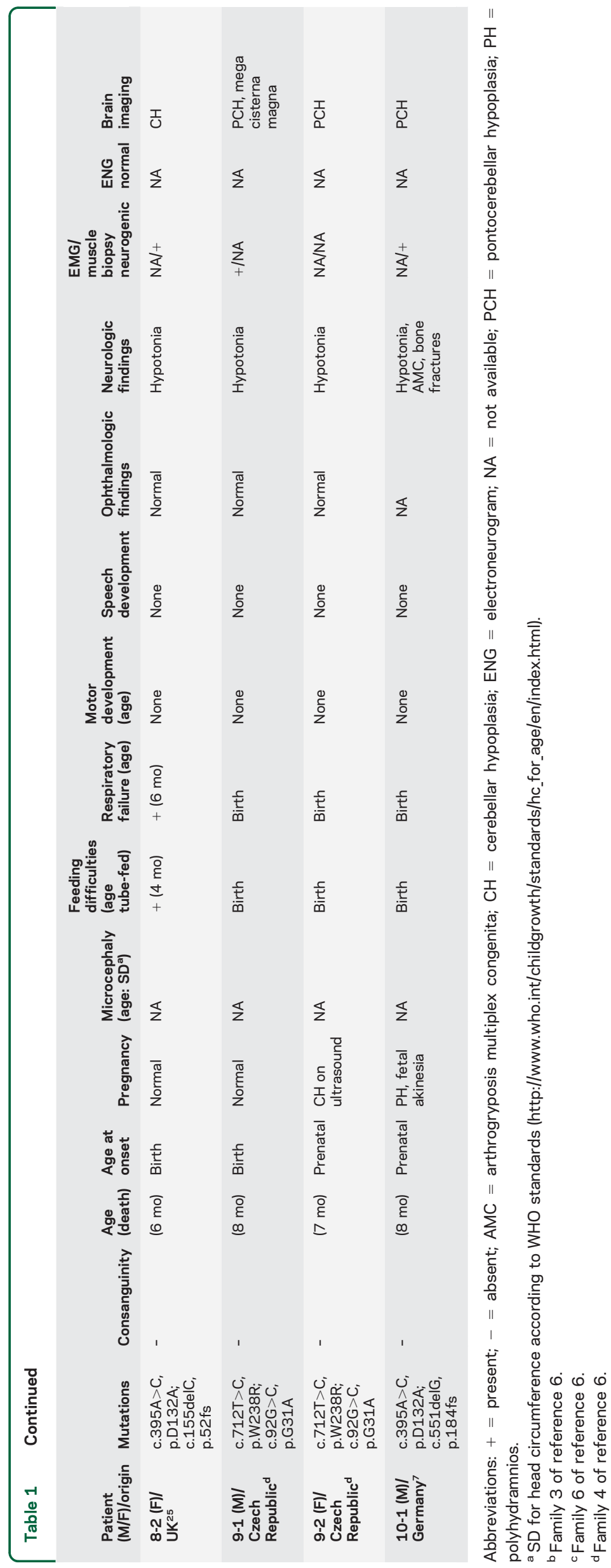

Families 4-6 (moderate PCH1): Patients showed a postnatal onset of rapidly progressive cerebellar volume loss and achieved no psychomotor developmental milestones. Respiratory failure was reported in late stages of the disease and was only rarely a cause of death, which occurred at age 1-3 years. Moderate $\mathrm{PCH} 1$ was correlated with c.395A $>\mathrm{C}$ in combination with an insertion mutation c.226dupG, a splice site mutation c.475-12A>G, and a mutation disrupting the start codon $\mathrm{c} .2 \mathrm{~T}>\mathrm{C}$.

Families 7-10 (severe PCH1): Patients had a prenatal or congenital onset of cerebellar, pontine, and midbrain degeneration. They showed severe hypotonia and tongue fasciculations, while oculomotor dysfunction or other signs of cerebellar ataxia were not recorded. Most patients had postnatal respiratory failure leading to early death within the first year even under constant ventilation. Severe PCH1 was correlated with missense mutations distinct from c.395A $>\mathrm{C}$ (families 7 and 9) or with c.395A $>\mathrm{C}$ in combination with deletion mutations in families 8 and 10. Patient 7-1 with a homozygous missense mutation c.92G $>C$ survived under permanent ventilation from the 5 th month into the second year of life but had a clinical severity similar to family 8 .

Brain imaging in mild PCH1 showed hypoplasia of the cerebellar hemispheres with preserved folia and a small but well-structured pons (figure 3, A and B). In moderate $\mathrm{PCH} 1$, larger structural defects in the posterior fossa like mega cisterna and retrocerebellar cyst were seen (figure 3, C and D). In severe PCH1, a more pronounced reduction of all cerebellar structures including pons and brainstem was documented (figure 3E). Progressive neurodegeneration results in a marked reduction of cerebellum, pons, and brainstem in severe and late stages of the disease (figure e-1, a and b). In patient 9-2, who was thoroughly examined during intrauterine development after the death of an affected sibling (patient 9-1), initial neuroimaging showed normal findings in the 22nd week of gestation, while visible cerebellar hypoplasia was documented in the 30th week of gestation (figure e-1, c-e).

In our cohort there were 23 patients of 17 families who did not show EXOSC3 mutations (table e-2). Prenatal onset, congenital respiratory and feeding difficulties, joint contractures, and early death were rarely recorded in EXOSC3 mutations but were typical features among the mutation-negative patients (table 2). Abnormal oculomotor function (strabismus, nystagmus, oculomotor apraxia) was commonly observed in patients surviving beyond infancy ( $>1$ year) and was therefore more frequently documented in the mutation-positive group (29\% vs $17 \%)$. In young infants who died early, it might have been difficult to detect oculomotor 
A

Exon 1

2

3

4

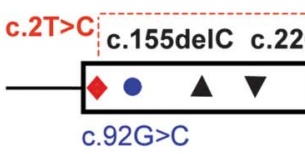

B

H. sapiens
C.lupus
M.musculus
G.gallus
D.rerio
D.melanogaster
C.elegans
A.thaliana
S.pombe
S.cerevisiae
K.lactis
N.crassa

G31A
LGQVVLPGEELLLPE
LDQVVLPGEELLLPE
LNQVVLPGEELVLPD
VGQVVLPGDVLLLPA
IGDVVLPGDLLFS--
--TIVMPGERI----
--TVYLPGDVI----
--QTVVPGDVV----
--SYYFPGERI----
--TFIFPGDSF----
---LLLPGDVI----
--LVVLPGETI----

c.551delG

(A) Newly identified (bold) and previously reported mutations in 15 of 27 unrelated families with pontocerebellar hypoplasia with spinal muscular atrophy (PCH1) in EXOSC3 spanning 4 exons (open boxes). $\downarrow$, shown in red, is a mutation in the start code that shifts the translation initiation 520 bases downstream, thus missing the first 174 amino acid residues. mutations; $\boldsymbol{\Delta}$, deletion mutation; $\boldsymbol{\nabla}$, insertion mutation; star, splice site mutation. (B) Alignment of protein sequences encoded by EXOSC3 in human and orthologous genes in other eukaryotes, showing alteration of evolutionarily conserved amino acid residues in bold; the altered amino acid residue and the corresponding missense mutation are represented by matching color.

dysfunction. There was no evidence of a peripheral neuropathy in the mutation-positive group but in some patients without mutations. Motor nerve conduction velocities were markedly delayed (as low as 6 to $9 \mathrm{~m} / \mathrm{s}$ in patient 17-1) or action potentials could not be elicited in motor or sensory nerves (patients 16-1, 17-2, 20-1). Sural nerve biopsy was only performed in patient 171 and did not give evidence of demyelination but showed loss of large myelinated axons as outlined previously. ${ }^{7}$ Brain imaging and autopsy findings revealed

Figure 2 Clinical impression of the longest surviving patients in this cohort
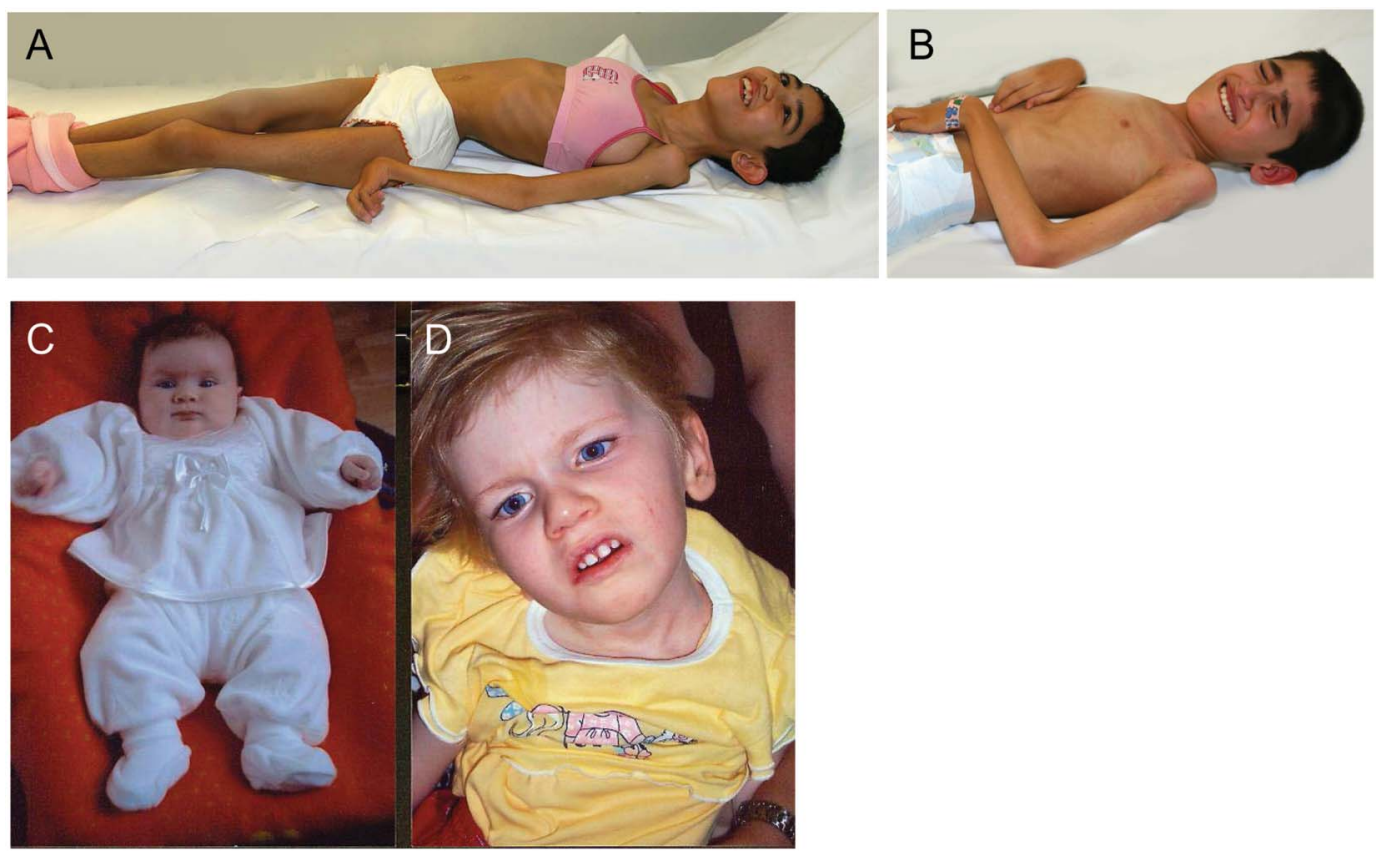

(A) Patient 1-1 at 15 years. (B) Patient 1-2 at 11 years, demonstrating microcephaly, inability to direct gaze, and profound muscle atrophy. Patient 3-1 at different ages: (C) 3 months with normal appearance, (D) 4 years with generalized muscular hypotonia, no head control, and inability to track. 

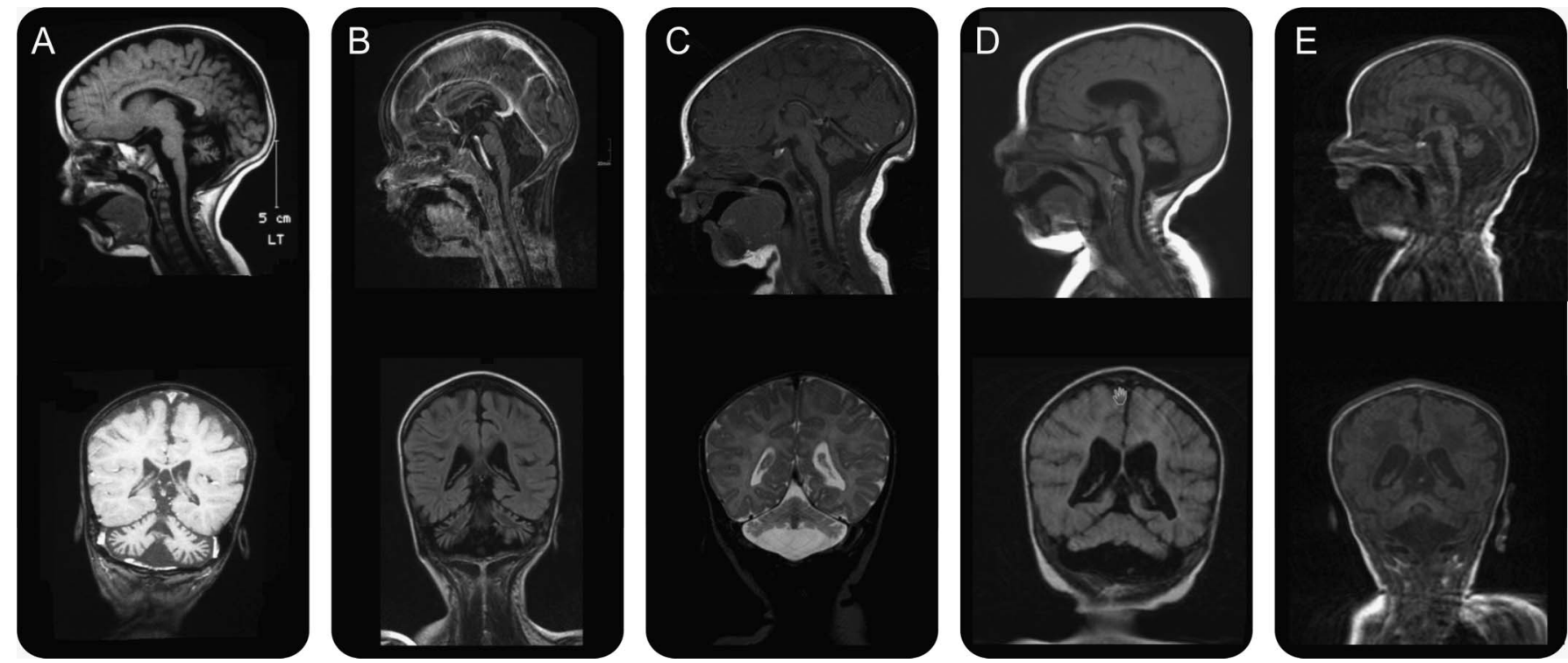

MRI of the brain in 5 patients with different subtypes of pontocerebellar hypoplasia with spinal muscular atrophy (PCH1) and confirmed EXOSC3 mutations, mild PCH1 (A, patient 2-1, age 1 7/12 years; $B$, patient 3-1, age 4 4/12 years), moderate PCH1 (C, patient 6-1, age 2 weeks; $D$, patient 7-1, age 4.5 months), and severe $\mathrm{PCH} 1$ (E, patient 9-1, age 2 weeks). In $A$ and $B$, there is cerebellar volume loss but all cerebellar lobules are present and the brainstem is relatively preserved. In $C$ and $D, M R I$ demonstrated larger structural defects in the posterior fossa compared to $A$ and $B$. In $E$, there is marked volume loss of the cerebellar structures as well as the pons and brainstem. Top row: sagittal sections; bottom row: coronal sections.

\begin{tabular}{|c|c|c|c|}
\hline \multicolumn{4}{|c|}{$\begin{array}{l}\text { Clinical features of } 15 \text { patients with EXOSC } 3 \text { gene mutations in comparison to } 23 \text { patients without } \\
\text { mutations }^{a}\end{array}$} \\
\hline Item & & Patients with mutations $(n=15)$ & Patients without mutations $(n=23$ ) \\
\hline \multicolumn{2}{|c|}{ Median age at onset (range) } & Birth (prenatal-6 mo) & Prenatal (prenatal-12 mo) \\
\hline \multicolumn{2}{|c|}{ Median age at death (range) } & $9 \mathrm{mo}(4 \mathrm{mo}-5 \mathrm{y})$ & $3 \mathrm{mo}(2 \mathrm{~h}-4 \mathrm{y})$ \\
\hline \multicolumn{2}{|c|}{ Longest survival, y } & 20 & 7 \\
\hline \multicolumn{2}{|c|}{ Pregnancy abnormal } & 2/15 (13) & $11 / 23(48)$ \\
\hline \multicolumn{2}{|c|}{ Polyhydramnios } & $1 / 15(7)$ & $11 / 23(48)$ \\
\hline \multicolumn{2}{|c|}{ Fetal akinesia } & $1 / 15(7)$ & $1 / 23(4)$ \\
\hline \multicolumn{2}{|c|}{ Joint contractures } & - & 1/23 (4) \\
\hline \multicolumn{2}{|c|}{ Arthrogryposis multiplex congenita } & 2/15 (13) & $7 / 23$ (30) \\
\hline \multicolumn{2}{|c|}{ Progressive microcephaly } & $8 / 12(67)$ & $3 / 13$ (23) \\
\hline \multicolumn{2}{|c|}{ Failure to thrive from birth } & $3 / 14(21)$ & $12 / 19(63)$ \\
\hline \multicolumn{2}{|c|}{ Respiratory failure from birth } & $3 / 14(21)$ & $15 / 21(71)$ \\
\hline \multicolumn{2}{|c|}{ Absent motor development } & $11 / 14(79)$ & 19/23 (83) \\
\hline \multicolumn{2}{|c|}{ Absent speech development } & $14 / 15(93)$ & 23/23 (100) \\
\hline \multicolumn{2}{|c|}{ Nystagmus } & $4 / 14(29)$ & $0 / 12(0)$ \\
\hline \multicolumn{2}{|c|}{ Strabismus } & $4 / 14$ (29) & 2/12 (17) \\
\hline \multicolumn{2}{|c|}{ Muscle tone abnormal } & $15 / 15(100)$ & $23 / 23(100)$ \\
\hline \multicolumn{2}{|c|}{ Hypotonia } & $13 / 15(87)$ & 21/23 (91) \\
\hline \multicolumn{2}{|c|}{ Increased muscle tone/spasticity } & 2/15 (13) & 2/23 (9) \\
\hline \multicolumn{2}{|l|}{ Epilepsy } & $3 / 15(20)$ & 5/23 (22) \\
\hline
\end{tabular}


similar pontocerebellar volume loss and nerve cell depletion in the mutation-positive and the mutation-negative group.

DISCUSSION Our PCH1 series demonstrates variability of clinical severity and broad spectrum of cerebellar and midbrain structural defects. PCH1 results from a profound underdevelopment of the neocerebellum and its adjacent structures, and also includes motor neuron degeneration in the spinal cord. ${ }^{3}$ The hypoplastic cerebellum has a reduced number of folia, while the cerebellar shape is not altered. The developmental disturbance affects mainly the phylogenetically new parts of the cerebellum (i.e., the neocerebellum) with relative sparing of the vermis and the flocculonodular lobules. Since cerebellar development starts at about 5 gestational weeks and migration of neurons is not completed until 15 postnatal months, ${ }^{9}$ this can explain why some patients with PCH1 display normal supratentorial and infratentorial brain structures by imaging methods at birth followed by a rapid loss of cerebellar hemispheres within weeks or months. Given the identical germinal zones, the association of pontine and cerebellar hypoplasia is common. ${ }^{10}$ As such $\mathrm{PCH}$ is characterized by neuronal loss in the ventral pons, inferior olive, and cerebellum, with onset in utero but continuing after birth. ${ }^{11}$ The cerebellum plays crucial roles in sensory integration and motor planning as well in higher cognitive processing such as attention and language acquisition. ${ }^{12}$ This explains the profound psychomotor retardation in patients with $\mathrm{PCH}$.

All genes so far identified as mutated in the other PCH subtypes (TSEN, RARS2, SEPSECS) are involved in tRNA processing, ${ }^{3}$ and that maturing neurons are especially vulnerable for defects in protein synthesis has been hypothesized to account for the clinical phenotype. The clinical and pathoanatomic distinction among the different $\mathrm{PCH}$ subtypes can also be difficult, and in 1 patient with PCH1 mutations in TSEN were reported, ${ }^{5}$ further complicating a reasonable classification of $\mathrm{PCH}$. Of note, a child from a consanguineous family of Ashkenazi Jewish origin was diagnosed with PCH1 and had a homozygous nonsense mutation identified in the VRK1 gene, which encodes a serine/ threonine kinase that phosphorylates p53 and CREB and is essential for nuclear envelope formation. ${ }^{4}$ The clinical presentation of this child and siblings (who were not genetically characterized) differed from $\mathrm{PCH}$ in that these patients had severe microcephaly at birth while mental development was normal or only mildly impaired. Ataxia and muscle weakness occurred later in the disease course and the onset of cerebellar degeneration remained unclear. ${ }^{4}$

The EXOSC3 gene encodes a core component of the RNA exosomes that process and degrade RNA and thereby regulate the activity of gene expression.
How mutations in EXOSC3 lead to PCH1 has not yet been elucidated. As shown by the morpholino knockdown experiments in zebrafish, the missense mutations appear to be hypomorphic. ${ }^{6}$ No patient has been observed to harbor biallelic null mutations; it is likely that homozygous null mutations of EXOSC3 are incompatible with life and result in early embryologic lethality. ${ }^{6}$ Patients harboring biallelic EXOSC3 mutations demonstrate profound loss of cerebellar and spinal motor neurons while heterozygous mutation carriers are asymptomatic, suggesting that a minimum expression of EXOSC3 is essential to the development and survival of cerebellar and motor neurons. ${ }^{6}$

By comparing the clinical and pathoanatomic features of patients with $\mathrm{PCH} 1$ with and without EXOSC3 mutations (table 2) and by surveying the literature, we make the following observations.

Birth measurements are normal in mutation-positive patients, i.e., primary microcephaly at birth as described in some patients ${ }^{4,5,13}$ implies another genetic cause in PCH1. Two-thirds of patients with EXOSC3 mutations develop progressive microcephaly ranging from mild to moderate $(-2.0$ to $-3.5 \mathrm{SD})$. Psychomotor retardation is profound; no EXOSC3 mutation-positive patient had motor or speech development above the level of a few-months-old infant. Initial normal psychomotor development or normal cognitive functions followed by cerebellar and spinal muscular atrophy as described in a handful of patients in the literature ${ }^{4,6,14,15}$ are likely not associated with EXOSC3 dysfunction. Muscle tone and strength is generally reduced since birth, except in family 1 with initial spasticity followed by hypotonia and flaccid pareses later in the disease course. Thus, it may be useful to search for EXOSC3 mutations in other PCH subtypes which are characterized by increased muscle tone and choreiform or dystonic movements. Epileptic seizures were uncommon in both the mutation-positive and -negative groups and did not follow a specific pattern. Abnormal oculomotor function (strabismus, nystagmus, oculomotor apraxia) was commonly observed in patients surviving beyond infancy. Additional organ involvement such as gonadal dysgenesis, ${ }^{16}$ also seen in patient 23-2 (table e- $2^{8}$ ), retinal degeneration or optic nerve atrophy, ${ }^{5}$ hepatic fibrosis, and cystic kidney disease $^{17}$ are also not yet reported in patients with EXOSC3 mutations. Mesangiocapillary glomeronephritis was diagnosed in a mutation-positive Australian patient ${ }^{6}$ (patient 4 in reference 18). Since this is the only reported case to date, the kidney disease might have been a coincidental finding. EXOSC3-associated PCH1 shows a variable lifespan, ranging from a few months to adulthood. In particular, patients with homozygous c.395A $>\mathrm{C}$ mutations have a chronic course with minimal involvement of the pons, as noted in previously described families. ${ }^{6}$ The clinical features 
associated with "classical" PCH1 with prenatal onset, congenital respiratory and feeding difficulties, arthrogryposis multiplex congenita, and neonatal death are infrequent in patients with EXOSC3 mutations but were most prevalent among the mutation-negative patients and also in the literature. ${ }^{1,19-24}$

Electromyographic examinations give evidence of neurogenic changes in the muscle in all patients based on the diagnostic entry criteria. Nerve conduction studies were normal in all patients with EXOSC3 mutations and in the majority of patients without. In few patients without mutations motor nerve conduction velocities were delayed or action potentials could not be elicited in motor or sensory nerves. While the absence of an electric response by nerve conduction studies might be of technical nature in small children, markedly reduced conduction velocities, as also reported in some patients from the literature, , $18,21,23,24$ or reduction of demyelinated nerve fibers in sural nerve biopsies ${ }^{19,24}$ might point toward distinct genetic entities.

Neuroimaging in EXOSC3 mutation-positive patients shows a marked reduction of the cerebellar hemispheres giving rise to an enlarged fourth ventricle, sometimes with the impression of a mega cisterna magna, and a retrocerebellar cyst. In severe cases and as the disease progresses, pons and brainstem reduction become visible on MRI. Initially the cortical structures are normal, thus other brain malformation $s^{18}$ or marked brain atrophy from the beginning giving rise to enlarged ventricles as seen in some nonmutated families suggest other disease causes.

Autopsy findings in patients with and without EXOSC3 mutations did not reveal different cerebellar, brainstem, and spinal cord findings on the basis of the medical records made available. Generalized brain atrophy or white matter changes point toward entities involving more cerebral structures than seen in EXOSC3 mutation-positive patients.

In this large series of PCH1 families, mutations in EXOSC3 are an important cause of the disease and account for approximately one-third of the families. Although still affected with progressive neurogenic muscular atrophy and global developmental delay with marked cerebellar atrophy, homozygous c.395A $>C$ mutations in EXOSC3 are associated with relative sparing of the brainstem and survival beyond early childhood, with several individuals reaching teenage and early adulthood. The clinical manifestations in association with other EXOSC3 mutations were more severe with early mortality, suggesting that these mutations may exert a more detrimental impact on the gene product than c.395A $>$ C. The yield for mutation screening was low in those with primary microcephaly, primary hypoventilation, normal or mildly impaired psychomotor development, abnormal nerve conduction studies, or histologic evidence of peripheral neuropathy, and widespread neuroimaging abnormalities beyond the posterior fossa. Further EXOSC3 mutation analyses may be considered in other PCH types or patients with milder olivopontocerebellar atrophy with or without anterior horn cell disease. Molecular genetic diagnosis is now possible for a large subgroup of patients with PCH1. Counseling and prenatal or preimplantation diagnosis can be offered in genetically characterized families.

\section{AUTHOR CONTRIBUTIONS}

Sabine Rudnik-Schöneborn: study concept and design, analysis and interpretation. Jan Senderek: analysis and interpretation, critical revision of manuscript. Joanna C. Jen: analysis and interpretation, critical revision of the manuscript. Gunnar Houge: acquisition of data. Pavel Seeman: acquisition of data, critical revision of manuscript. Alena Puchmajerová: acquisition of data. Luitgard Graul-Neumann: acquisition of data. Ulrich Seidel: acquisition of data. Rudolf Korinthenberg: acquisition of data. Janbernd Kirschner: acquisition of data. Jürgen Seeger: acquisition of data. Monique M. Ryan: acquisition of data. Francesco Muntoni: acquisition of data. Maja Steinlin: acquisition of data. Laszlo Sztriha: acquisition of data. Jaume Colomer: acquisition of data. Christoph Hübner: acquisition of data. Knut Brockmann: acquisition of data. Lionel Van Maldergem: acquisition of data. Manuel Schiff: acquisition of data. Andreas Holzinger: acquisition of data. Peter Barth: acquisition of data. William Reardon: acquisition of data. Michael Yourshaw: acquisition of data. Stanley F. Nelson: acquisition of data. Thomas Eggermann: acquisition of data. Klaus Zerres: study supervision.

\section{ACKNOWLEDGMENT}

The authors thank the families who supported this research.

\section{STUDY FUNDING}

Supported by the Deutsche Forschungsgemeinschaft (RU 746/1-1) for S.R.-S. and K.Z. and by IZKF Biomat (project N5-4) for S.R.-S. and J.S. The genotyping and analytical work was supported by the Bioinformatics and Genomics Core of the UCLA Muscular Dystrophy Core Center (NIH/ NIAMS P30AR057230 to S.F.N.) within the Center for Duchenne Muscular Dystrophy. Also supported by NEI EY015311 and NINDS NS064183 (J.C. J.). P.S. is supported by IGA MH NS 11523-4. F.M. is supported by the Great Ormond Street Children's Charity.

\section{DISCLOSURE}

The authors report no disclosures relevant to the manuscript. Go to Neurology.org for full disclosures.

Received May 25, 2012. Accepted in final form October 5, 2012.

\section{REFERENCES}

1. Norman RM. Cerebellar hypoplasia in Werdnig-Hoffmann disease. Arch Dis Child 1961;36:96-101.

2. Barth PG. Pontocerebellar hypoplasia: an overview of a group of inherited neurodegenerative disorders with fetal onset. Brain Dev 1993;15:411-422.

3. Namavar Y, Barth PG, Poll-The BT, Baas F. Classification, diagnosis and potential mechanisms in pontocerebellar hypoplasia. Orphanet J Rare Dis 2011;6:50.

4. Renbaum P, Kellerman E, Jaron R, et al. Spinal muscular atrophy with pontocerebellar hypoplasia is caused by a mutation in the VRK1 gene. Am J Hum Genet 2009;85: 281-289.

5. Simonati A, Cassandrini D, Bazan D, Santorelli FM. TSEN54 mutation in a child with pontocerebellar hypoplasia type 1. Acta Neuropathol 2011;121:671-673.

6. Wan J, Yourshaw M, Mamsa H, et al. Mutations in the RNA exosome core component EXOSC3 cause pontocerebellar 
hypoplasia and spinal motor neuron degeneration. Nat Genet 2012;44:704-708.

7. Rudnik-Schöneborn S, Sztriha L, Aithala GR, et al. Extended phenotype of pontocerebellar hypoplasia with infantile spinal muscular atrophy. Am J Med Genet A 2003;117A:10-17.

8. Muntoni F, Goodwin F, Sewry C, et al. Clinical spectrum and diagnostic difficulties of infantile ponto-cerebellar hypoplasia type 1. Neuropediatrics 1999;30:243-248.

9. Patel S, Barkovich AJ. Analysis and classification of cerebellar malformations. AJNR Am J Neuroradiol 2002;23:1074-1087.

10. Rodriguez CI, Dymecki SM. Origin of the precerebellar system. Neuron 2000;27:475-486.

11. Millen KJ, Gleeson JG. Cerebellar development and disease. Curr Opin Neurobiol 2008;18:12-19.

12. Glickstein M, Doron K. Cerebellum: connections and functions. Cerebellum 2008;7:589-594.

13. Tsao C-Y, Mendell J, Sahenk Z, et al. Hypotonia, weakness, and pontocerebellar hypoplasia in siblings. Semin Pediatr Neurol 2008;15:151-153.

14. Lev D, Michelson-Kerman M, Vinkler C, et al. Infantile onset progressive cerebellar atrophy and anterior horn cell degeneration: a late onset variant of PCH-1? Eur J Paediatr Neurol 2008;12:97-101.

15. Sanefuji M, Kira R, Matsumoto K, et al. Autopsy case of later-onset pontocerebellar hypoplasia type I: pontine atrophy and pyramidal tract involvement. J Child Neurol 2010;25:1429-1434.

16. Kamoshita S, Takei Y, Miyao M, et al. Pontocerebellar hypoplasia associated with infantile motor neuron disease (Norman's disease). Pediatr Pathol 1990;10:133-142.
17. Harding BN, Dunger DB, Grant DB, Erdohazi M. Familial olivopontocerebellar atrophy with neonatal onset: a recessively inherited syndrome with systemic and biochemical abnormalities. J Neurol Neurosurg Psychiatry 1988;51:385-390.

18. Ryan MM, Cooke-Yarborough CM, Procopis PG, Ouvrier RA. Anterior horn cell disease and olivopontocerebellar hypoplasia. Pediatr Neurol 2000;23:180-184.

19. Chou SM, Gilbert EF, Chun RW, et al. Infantile olivopontocerebellar atrophy with spinal muscular atrophy (infantile OPCA+SMA). Clin Neuropathol 1990;9:21-32.

20. Weinberg AG, Kirkpatrick JB. Cerebellar hypoplasia in Werdnig-Hoffmann disease. Dev Med Child Neurol 1975; 17:511-516.

21. Goutières F, Aicardi J, Farkas E. Anterior horn cell disease associated with pontocerebellar hypoplasia in infants. J Neurol Neurosurg Psychiatry 1977;40:370-378.

22. Moerman P, Barth P. Olivo-ponto-cerebellar atrophy with muscular atrophy, joint contractures and pulmonary hypoplasia of prenatal onset. Virchows Arch A Pathol Anat Histopathol 1987;410:339-345.

23. De Leon GA, Grover WD, D’Cruz CA. Amyotrophic cerebellar hypoplasia: a specific form of infantile spinal atrophy. Acta Neuropathol 1984;63:282-286.

24. Görgen-Pauly U, Sperner J, Reiss I, et al. Familial pontocerebellar hypoplasia type I with anterior horn cell disease. Eur J Paediatr Neurol 1999;3:33-38.

25. Dubowitz V, Daniels RJ, Davies KE. Olivopontocerebellar hypoplasia with anterior horn cell involvement (SMA) does not localize to chromosome 5q. Neuromuscul Disord 1995;5: 25-29.

\section{Visit the Neurology ${ }^{\circledR}$ Resident \& Fellow Web Site}

Click on Residents \& Fellows tab at www.neurology.org.

Now offering:

- Neurology ${ }^{\circledR}$ Resident \& Fellow Editorial team information

- "Search by subcategory" option

- E-pearl of the Week

- RSS Feeds

- Direct links to Continuum ${ }^{\circledR}$, Career Planning, and AAN Resident \& Fellow pages

- Recently published Resident \& Fellow articles

- Podcast descriptions

(1) Find Neurology ${ }^{\circledR}$ Residents \& Fellows Section on Facebook: http://tinyurl.com/c5xkprg

twitter Follow Neurology ${ }^{\circledR}$ on Twitter: http://twitter.com/GreenJournal 